Chronic Obstructive Pulmonary Diseases:

Journal of the COPD Foundation

Review

\title{
The Role of Guaifenesin in the Management of Chronic Mucus Hypersecretion Associated with Stable Chronic Bronchitis: A Comprehensive Review
}

Jill A. Ohar, $\mathrm{MD}^{1}$ James F. Donohue, $\mathrm{MD}^{2}$ Selwyn Spangenthal, $\mathrm{MD}^{3}$

\begin{abstract}
Chronic obstructive pulmonary disease is the third leading cause of death and disease burden worldwide. It includes a spectrum of diseases including chronic bronchitis which is characterized by overproduction, hypersecretion and decreased elimination of mucus. Chronic bronchitis has numerous clinical consequences, including predisposition to lower respiratory tract infections, accelerated decline in lung function, increased exacerbation rate and decreased health-related quality of life.

Although the inflammatory mechanisms responsible for mucus cell metaplasia in chronic obstructive pulmonary disease and stable chronic bronchitis are poorly understood, the main goals of therapy are to decrease mucus hypersecretion by controlling inflammation and to increase mucus clearance. Non-pharmacological measures include smoking cessation and chest physiotherapy. Pharmacological interventions include expectorants and mucolytics together with long-acting beta2-adrenergic receptor agonists, anticholinergics, glucocorticoids, phosphodiesterase-4 inhibitors, antioxidants, and antibiotics.

Guaifenesin is an expectorant that is thought to increase hydration and decrease viscosity of mucus leading to improved clearance of accumulated secretions from the upper and lower airway. Although guaifenesin has a Food and Drug Administration Over-the-Counter (OFC) Monograph indication to "help loosen phlegm (mucus) and thin bronchial secretions in patients with stable chronic bronchitis," there is limited published evidence of either mechanism of action or clinical efficacy in this disease state. Here we review the pathophysiology and consequences of chronic mucus hypersecretion and examine the evidence for the use of guaifenesin in patients with stable chronic bronchitis.
\end{abstract}

\footnotetext{
Abbreviations: chronic obstructive pulmonary disease, COPD; chronic bronchitis, CB; stable chronic bronchitis, SCB; glycerol guaiacolate ether/guaifenesin, GGE; chronic mucus hypersecretion, CMH; Food and Drug Administration, FDA; over-the-counter, OTC

Funding Support: Not applicable

Date of Acceptance: September 25, 2019

Citation: Ohar JA, Donohue JF, Spangenthal S. The role of guaifenesin in the management of chronic mucus hypersecretion associated with stable chronic bronchitis: a comprehensive review. Chronic Obstr Pulm Dis. 2019;6(4):341-349. doi: https://doi.org/10.15326/ jcopdf.6.4.2019.0139
}

1 Section of Pulmonary, Critical Care, Allergy, and Immunological Diseases, Wake Forest University School of Medicine, WinstonSalem, North Carolina

2 Division of Pulmonary Diseases and Critical Care, Department of Medicine, University of North Carolina, Chapel Hill

3 Internal Medicine \& Pulmonology, Charlotte Lung \& Health Center, Charlotte, North Carolina

\section{Address correspondence to:}
Jill Ohar, MD
Email: johar@wakehealth.edu
Phone: 336-406-6733

\section{Keywords:}

chronic obstructive pulmonary disease; COPD; chronic bronchitis; stable chronic bronchitis; chronic mucus hypersecretion; guaifenesin; expectorants 


\section{Introduction}

Chronic obstructive pulmonary disease (COPD) is defined by the World Health Organization as "chronic obstruction of lung airflow that interferes with normal breathing and is not fully reversible." 1 More commonly, COPD describes a group of chronic, progressive, airflow limiting diseases, including chronic bronchitis (CB) and emphysema. As such, the disease term CB is rarely used today, as it is included within the umbrella COPD diagnosis. ${ }^{2}$ Nevertheless, there is clinical value in separating out $C B$ as a phenotype to identify patients with a beneficial response to therapy ${ }^{3}$ and stable chronic bronchitis (SCB), to better contextualize the patient population that may benefit from guaifenesin/ glycerol guaiacolate ether (GGE).

The CB definition used in epidemiologic studies has been variable, but the classic definition is chronic cough and sputum production for at least 3 months per year for 2 consecutive years. ${ }^{3}$ For the purpose of future, prospective clinical studies the authors suggest SCB be defined as a chronic productive cough that occurs daily for at least 3 months in 2 consecutive years, in a patient who has not had an acute exacerbation within the previous 4 weeks; where an acute exacerbation of chronic bronchitis is defined as an acute worsening of a patient's symptoms, beyond normal day-to-day variations, necessitating a change in treatment with antibiotics and/or corticosteroids.

\section{Review of Mucus Hypersecretion in COPD}

The surface liquid covering the epithelial lining of the airways is known to comprise at least 2 layers: the mucus (gel) layer and the periciliary layer surrounding the cilia which consists of a gel mesh of cell-tethered mucins and polysaccharides. ${ }^{4,5,6}$ Mucus consists of a mixture of fluid and secretions from surface epithelium and submucosal glands and is predominantly comprised of water (95\%) glycoproteins (2\%-3\%), proteoglycans $(0.1 \%-0.5 \%)$, lipids ( $0.3 \%-0.5 \%)$, proteins, and DNA. ${ }^{7}$ The glycoprotein component consists of secreted mucins, particularly the large polymeric structures MUC5AC and MUC5B, which account for the rheologic properties of mucus. ${ }^{8}$

Under normal conditions, mucus protects the airway. Hydration of mucus affects its viscous and elastic properties, which in turn determines how effectively it is cleared by ciliary action and cough. ${ }^{9}$ Effective mucus clearance is essential for lung health, whereas abnormalities in mucus production and qualitative properties such as mucus hydration are central to the pathophysiology of airway disease including $\mathrm{CB} .{ }^{10}$ Certain stress conditions including smoking, infection, pathogenic factors, and oxidative stress result in secretory cell hypertrophy and goblet cell hyperplasia in the airway, and subsequent overproduction of mucus. Pathological mucus is not easily cleared given that solids may increase up to $15 \%$ resulting in higher viscosity and elasticity. ${ }^{9}$ Additionally, in CB, mucus osmotic pressure is increased, resulting in compression of the cilia, slowing of mucociliary transport and delayed mucociliary clearance. ${ }^{10}$ Furthermore, in CB there is a direct correlation between forced expiratory volume in 1 second and the percentage solids of mucus, demonstrating a strong relationship between disease progression and mucus abnormalities. ${ }^{10}$

The conversion from healthy to pathologic mucus occurs by multiple mechanisms that change its hydration and biochemical constituents including abnormal secretion of sodium chloride and water, increased production of mucins, infiltration of mucus with neutrophils, macrophages, polymorphonuclear leukocytes, other pro-inflammatory cells, and heightened bronchovascular permeability. The persistent accumulation of mucus results from a combination of overproduction and decreased mucociliary clearance that can lead to inflammation and infection. ${ }^{11} \mathrm{CB}, \mathrm{SCB}$ and $\mathrm{COPD}$ are conditions characterized by chronic mucus hypersecretion $(\mathrm{CMH})$, ciliary dysfunction and impaired mucus clearance. ${ }^{11,12}$ $\mathrm{CMH}$ is not only a clinical symptom but also an independent risk factor for disease progression and poor prognosis of patients with chronic inflammatory airway diseases. $\mathrm{CMH}$ is associated with more frequent exacerbations and hospitalizations, ${ }^{13}$ lung function decline, ${ }^{14}$ decreased health-related quality of life ${ }^{15}$ and higher mortality in patients with COPD. ${ }^{16}$

Cigarette smoking is a major trigger of $\mathrm{CMH}$ and is the leading risk factor for death in patients with COPD. ${ }^{14}$ Cigarette smoke induces an epidermal growth factor receptor cascade, which results in the production of mucins and goblet cell hyperplasia. ${ }^{17}$

$\mathrm{CMH}$ becomes increasingly common with age. Allinson et $\mathrm{l}^{18}$ concluded that the severity of $\mathrm{CMH}$ associated symptoms in middle age among active 
smokers is predictive of the risk of airflow limitation in later life and that the longer $\mathrm{CMH}$ is present the greater the decline in lung function.

$\mathrm{CMH}$ and mucus accumulation in COPD reflects the failure of cough -the major rescue mucus clearance pathway. Button et al ${ }^{19}$ demonstrated how abnormal mucus and its interactions with the cell surface produce a failure of cough clearance. The authors identified mucus concentration-dependent cohesive and adhesive properties governed by mucus viscous energy dissipation as rate-limiting for the efficacy of cough clearance and demonstrated how returning mucus concentrations to normal ranges can restore cough efficacy. There are 2 objectives in the treatment of $\mathrm{CMH}$, namely, short-term relief of symptoms through improved mucus clearance and long-term benefit by altering or reversing the hypersecretory phentotype. $^{20}$ The use of mucoactive drugs to inhibit $\mathrm{CMH}$ and improve mucociliary clearance is therefore important in the treatment of SCB and the chronic bronchitic phenotype of COPD.

There are 4 main classes of mucoactive drugs: expectorants (which induce discharge or expulsion of mucus from the respiratory tract by coughing or sneezing), mucolytics (that decrease mucus viscosity), mucokinetics (that increase ciliary beat frequency) and mucoregulators (that regulate mucus secretion). ${ }^{21}$ Although some mucoactive drugs exhibit overlapping effects, only mucolytics and expectorants have a direct action on mucus properties. ${ }^{21}$ One such expectorant is guaifenesin (3-[2-methoxyphenoxy]-1,2-propanediol; [glycerol guaiacolate ether] [GGE]), an orally administered, OTC medication that is thought to help loosen and thin bronchial secretions and make cough more productive. The exact mechanism of action is unclear and studies to assess the effect of GGE on mucociliary and cough clearance have yielded conflicting results. ${ }^{22-35}$ (Table 1 ).

GGE is thought to exert its principal pharmacological action by stimulating receptors in the gastric mucosa, via the so-called neurogenic theory or gastro-pulmonary reflex. ${ }^{30-35}$ Animal studies have shown that GGE acts as an irritant ${ }^{27,33}$ to stimulate gastric vagal receptors which then trigger cholinergic parasympathetic reflexes resulting in vagal stimulation of respiratory tract fluid secretion. ${ }^{27}$ The result is an increase in volume and decrease in viscosity of bronchial secretions. Increased gastric vagal stimulation and subsequent vagal activity in the airways may enhance mucocilliary clearance. ${ }^{31,32}$ GGE may also directly stimulate vagal nerve endings in bronchial secretory glands and certain centers in the brain, which in turn enhance respiratory secretion flow. $^{22}$

Studies in patients with $\mathrm{CB}$ have demonstrated that guaifenesin reduces sputum surface tension ${ }^{23}$ and viscosity $^{24}$ and increases mucociliary clearance. ${ }^{24,25}$ GGE has also been shown to inhibit cough reflex sensitivity, ${ }^{26}$ suppress mucin production, increase mucociliary transport and decrease viscosity and elasticity of secretions. ${ }^{28,29}$

\section{Clinical Experience with Guaifenesin in SCB}

GGE is currently the only U.S. Food and Drug Administration (FDA)-approved expectorant in the United States. $^{22}$ It is available in tablet form for both immediate and extended release, as a single active ingredient in branded and generic cough medicines and as an ingredient in multi-symptom cough and cold products. The extended-release form is only available in tablet format (single ingredient and combinations) but the majority of marketed immediate-release products (single ingredient or combinations) are liquids (syrups).

GGE is included in the FDA's OTC Monograph for "Cold, Cough, Allergy, Bronchodilator and Anti-Asthmatic Drug Products for Over-theCounter Human Use" as an expectorant ${ }^{36}$ and also has a professional indication for SCB, although it is specifically excluded for use during acute exacerbations of $\mathrm{CB}$. The monograph indication for SCB was seemingly granted on the basis of 4 heterogenous, non-regulatory studies in patients with bronchopulmonary disease 20,23,37-39 one of which appears to be available only as an abstract. ${ }^{23}$

Hayes et al studied 21 patients with SCB and chronic productive cough. ${ }^{37}$ Patients self-administered a cough syrup containing $100 \mathrm{mg}$ GGE \& $1 \mathrm{mg}$ desoxyephedrine $\mathrm{HCl}$ versus placebo every 2-3 hours as needed and served as their own control during a placebo cross-over phase. No treatment-related differences were observed in pre-and post-intervention chest X-rays, blood counts, urinalysis, erythrocyte sedimentation rate or bacteriological examination of sputum. Subjective results included a significant 


\section{Table 1. Guaifenesin: Mechanism of Action and Effects on Mucus}

\begin{tabular}{|c|c|c|c|}
\hline $\begin{array}{c}\text { Ref } \\
\#\end{array}$ & $\begin{array}{l}\text { First Author } \\
\text { (Year) }\end{array}$ & Study Design & Observed Mechanism of Action \\
\hline 23 & $\begin{array}{l}\text { Chodosh S } \\
\text { (1964) }\end{array}$ & $\begin{array}{l}\text { Double-blind. } 100 \text { mg guaifenesin daily } \\
\text { for } 14 \text { days versus placebo. In vivo }\end{array}$ & Decreased sputum surface tension \\
\hline 24 & $\begin{array}{l}\text { Chodosh S } \\
\text { (1973) }\end{array}$ & $\begin{array}{l}\text { Double-blind, crossover. } 800 \text { or } \\
2400 \mathrm{mg} \text { /day guaifenesin for } 4 \text { weeks } \\
\text { versus placebo. In vivo }\end{array}$ & $\begin{array}{l}\text { Reduced surface tension and adhesiveness of mucus; } \\
\text { Improved mucociliary clearance }\end{array}$ \\
\hline 25 & $\begin{array}{l}\text { Thomson ML } \\
\text { (1973) }\end{array}$ & $\begin{array}{l}\text { Double-blind, crossover study. } 600 \mathrm{mg} \\
\text { guaifenesin versus placebo. In vivo. }\end{array}$ & Increased mucociliary clearance \\
\hline 26 & $\begin{array}{l}\text { Dicpinigaitis PV } \\
(2003)\end{array}$ & $\begin{array}{l}\text { Randomized, single-blind study. Single } \\
\text { dose of } 400 \text { mg guaifenesin versus } \\
\text { placebo. In vivo. }\end{array}$ & $\begin{array}{l}\text { Inhibition of cough reflex sensitivity through } \\
\text { (1) a central antitussive effect } \\
\text { (2) a peripheral effect whereby increased sputum volume } \\
\text { shields cough receptors in the respiratory epithelium } \\
\text { from tussive stimuli }\end{array}$ \\
\hline 27 & $\begin{array}{l}\text { Kagan L } \\
\text { (2009) }\end{array}$ & Rat model PK study & $\begin{array}{l}\text { Expectorant effect is mediated by stimulation of the } \\
\text { gastrointestinal tract and not by systemic exposure }\end{array}$ \\
\hline 28 & $\begin{array}{l}\text { Seagrave J } \\
(2011)\end{array}$ & In vitro & $\begin{array}{l}\text { Suppressed mucin production; Increased mucociliary } \\
\text { transport; Decreased mucus viscoelasticity }\end{array}$ \\
\hline 29 & $\begin{array}{l}\text { Seagrave J } \\
(2012)\end{array}$ & In vitro & $\begin{array}{l}\text { Inhibition of mucin [MUC5AC] production; Reduced } \\
\text { viscosity and elasticity of mucus; Increased mucociliary } \\
\text { transport rates }\end{array}$ \\
\hline
\end{tabular}

reduction in the severity of cough, reduced frequency of cough and decreased sputum viscosity, however no statistical analysis was included in the publication.

Chodosh et al studied 26 patients with SCB in a double-blind, placebo-controlled, cross-over study. Patients received 100mg GGE daily for 7 days during the active treatment phase. ${ }^{23}$ Initially, and after 7 days on each regimen, clinical assessment, ventilatory tests and sputum cytology, physical characteristics and chemical determinations were performed. The single page study report states that all of the data were statistically analyzed, but no statistical results are provided. Nevertheless, the author concluded that compared to placebo, the guaifenesin-treated patients experienced significant general clinical improvement, decreased sputum surface tension and decreased sputum viscosity.

Wójcicki et al studied 23 patients with SCB and chronic cough in a double-blind, cross-over study. Patients were treated for a total of 4 weeks, divided into $4 \times 7$-day treatment periods when they received either (1) Duopect (GGE $120 \mathrm{mg} /$ narcotine $17 \mathrm{mg}$ ), (2) narcotine $17 \mathrm{mg}$, (3) GGE $120 \mathrm{mg}$, (4) placebo. ${ }^{38}$ Of patients treated with the GGE/narcotine combination,
54\% experienced a subjective marked reduction in cough frequency and severity. A total of $79 \%$ of patients on GGE and $75 \%$ on combination therapy experienced subjective improvement in tenaciousness of sputum versus 34\% treated with narcotine and $21.8 \%$ with placebo.

Finiguerra et al conducted a double-blind placebocontrolled study of GGE in 40 patients with both acute and chronic bronchitis. Patients were treated for 15 days with either GGE $190 \mathrm{mg}$ or placebo syrup. $^{39}$ Efficacy of treatment was assessed on modifications in the characteristics of the expectorate (volume and appearance), difficulty expectorating and cough. Volume and appearance were expressed on a quantitative and semi-quantitative scale. In the group treated with GGE, results showed a reduction in the volume and viscosity of sputum, accompanied by improved ease of expectoration, reduced cough intensity and reduced dyspnea. However, due to the paucity of objective measurements versus subjective measurements and the failure to stratify those patients with acute and those with $C B$, no meaningful conclusions can be drawn.

Although these early studies suggest some degree 
of clinical benefit from GGE, they were performed in small cohorts, lack objective measurements and statistical analyses are missing or limited in value. Additionally, they all utilized doses significantly less than the currently accepted and FDA-approved daily dosing range of $1200-2400 \mathrm{mg}$ and none of the patients were treated for longer than 15 days, leaving many clinical questions unanswered.

Although efficacy data is lacking for GGE, postmarketing surveillance safety reports covering more than 50 years in the United States and around the world support a favorable safety profile. ${ }^{40} \mathrm{GGE}$ was not associated with any potentially related fatalities during a 17-year surveillance period or a subsequent 6-year detection period. The few published reports of serious adverse events have been in the context of chronic overdose and when it has been used in combination with other cough and cold medications where causality could not be established. Common side-effects include headache, dizziness and gastrointestinal disturbance at high doses. ${ }^{22,40}$

Four recently published, patient case studies ${ }^{41-44}$ in patients with COPD and CB have suggested that high dose GGE (1200-2400 mg/day), administered daily for 3 years or longer, might result in fewer infectious complications, reduced antibiotic use and improved quality of life, but these are all retrospective and single patient case reports.

\section{Discussion}

$C B$ is part of the umbrella term COPD and is characterized by overproduction, hypersecretion and decreased elimination of mucus. Patients with SCB can be defined as those with chronic productive cough for at least 3 months in 2 consecutive years, and no acute exacerbations in the previous 4 weeks. ${ }^{45}$

The CMH seen in this condition is associated with increased morbidity and mortality. Treating this symptom may provide relief, prevent complications and slow disease progression. One potential, frequently overlooked, therapeutic option is the expectorant GGE. More commonly perceived as an OTC cough and cold product, the authors were surprised to learn recently that it has had a professional prescribing indication for SCB since $1989 .^{36}$

Targeting $\mathrm{CMH}$ with the expectorant GGE is theoretically appealing. Mechanism of action data, although limited, suggest that GGE suppresses mucin production, acts as an irritant to gastric vagal receptors and recruits efferent parasympathetic reflexes that cause glandular exocytosis in the respiratory mucosa and reduces the viscosity of mucus secretion by reducing adhesiveness and surface tension as well as increasing hydration which helps to facilitate removal of accumulated mucus secretions from the upper and lower airway and increases mucociliary clearance. ${ }^{23-35}$ Airway pathophysiology studies utilizing new biological models of cough and technologies that can measure reduction of mucus adhesive and cohesive strength could help to more accurately elucidate the mechanism of action of GGE. ${ }^{19}$

Additionally, a better understanding of the role that central nervous system pathways play in regulating airway functions in both normal and disease states could provide novel therapeutic approaches for the treatment of $\mathrm{CMH}$ and other diseases whose clinical, biochemical, and pharmacological features indicate a pathophysiological link with the central nervous system. ${ }^{18}$

The clinical evidence supporting the use of GGE in $C B$ is weak. The 4 studies that formed the basis of the approval were all published prior to $1983,{ }^{23,37-39}$ involved small numbers of patients and do not meet today's scientific, methodological, statistical or regulatory evidence-based medicine standards.

This paucity of Level I evidence may be the reason why GGE is not included in any of the current U.S. or European COPD guidelines. It also suggests a clear need for further investigation of GGE in patients with SCB, specifically multicenter randomized, double blind, controlled studies using relevant, validated endpoints, standardized dosing and rigorous statistical analysis. We recommend that such studies should be carefully designed to investigate what, if any, role guaifenesin plays in the reduction of $\mathrm{CMH}$ symptoms and its impact on quality of life and health care resource utilization, as well as its possible effects on exacerbation frequency. The importance of symptoms is acknowledged by the current Global Initiative for Chronic Obstructive Lung Disease document, ${ }^{45}$ which recommends evaluating symptom burden and exacerbation history separately. There is also an increasing evidence base demonstrating that symptoms (including cough and sputum production) drive the burden of disease in COPD and have a substantial detrimental impact on health status, quality of life, and daily activities, and 
also contribute to increased anxiety and depression levels, increased risk of exacerbations, and worsened disease prognosis. ${ }^{46-53}$

In addition, given that antibiotic resistance and antibiotic-associated Clostridium difficile colitis are among the biggest public health challenges of our time, ${ }^{54,55}$ reduction of antibiotic use should be included as a secondary end point in all future COPD studies, as should health care utilization.

\section{Acknowledgements:}

The authors would like to thank Judi Miller for assistance with literature research, manuscript development and formatting.

Author Contributions: Dr. Ohar made substantial contributions to the conception, scope, content, writing and revision of the article. Drs. Donohue and Spangenthal contributed to the design and scope of the review article, data interpretation, reviewing and revising the manuscript. All authors reviewed and revised and approved the final draft for important intellectual content.

\section{Declaration of Interest:}

All authors participated in a stable chronic bronchitis clinical advisory board meeting supported by Reckitt Benckiser in September 2018 for which they received a consultancy fee. Additionally, J. Ohar reports serving on advisory boards for Theravance, GlaxoSmithKline, Sunovion, AstraZeneca, Mylan and Boehringer Ingelheim, conducting an investigator-initiated study for Sunovion and manuscript preparation for Theravance and Sunovion. 


\section{References}

1. World Health Organization (WHO). Chronic respiratory diseases: COPD definition. WHO website. https://www.who.int/ respiratory/copd/definition/en/

Published 2019. Accessed April 2019

2. Yawn BP. Is 'GOLD' standard for the management of COPD in clinical practice? Drugs Context. 2012; 2012:212243.

doi: https://doi.org/10.7573/dic.212243

3. Kim V, Criner GJ. Chronic bronchitis and chronic obstructive pulmonary disease. Am J Respir Crit Care Med. 2013;187(3):228237. doi: https://doi.org/10.1164/rccm.201210-1843CI

4. Randell SH, Boucher RC, University of North Carolina Virtual Lung Group. Effective mucus clearance is essential for respiratory health. Am J Respir Cell Mol Biol. 2006;35(1):20. doi: https://doi.org/10.1165/rcmb.2006-0082SF

5. Rubin BK. Physiology of airway mucus clearance. Respir Care. 2002;47(7):761-768.

6. Button B, Cai LH, Ehre C, et al. A periciliary brush promotes the lung health by separating the mucus layer from airway epithelia. Science. 2012;337(6097):937.

doi: https://doi.org/10.1126/science.1223012

7. Williams OW, Sharafkhaneh A, Kim V, Dickey BF, Evans CM. Airway mucus: from production to secretion. Am J Respir Cell Mol Biol. 2006;34(5):527.

doi: https://doi.org/10.1165/rcmb.2005-0436SF

8. Thornton DJ, Rousseau K, McGuckin MA. Structure and function of the polymeric mucins in airways mucus. Annuls Rev Physiol. 2008;70:459.

doi: https://doi.org/10.1146/annurev.physiol.70.113006.100702

9. Rose MC, Voynow JA. Respiratory tract mucin genes and mucin glycoproteins in health and disease. Physiol Rev. 2006; 86(1):245278. doi: https://doi.org/10.1152/physrev.00010.2005

10. Button B, Anderson WH, Boucher RC. Mucus hyperconcentration as a unifying aspect of the chronic bronchitic phenotype. Ann Am Thorac Soc. 2016;13(Suppl2):S156-162

11. Fahy JV, Dickey BF. Airway mucus function and dysfunction. $N$ Engl J Med. 2010;363(23):2233-2247.

doi: https://doi.org/10.1056/NEJMra0910061

$\overline{\text { 12. Shen Y, Huang S, Kang J, et al. Management of airway mucus }}$ hypersecretion in chronic airway inflammatory disease: Chinese expert consensus (English edition). Int J Chron Obstruct Pulmon Dis. 2018;13:399-407.

doi: https://doi.org/10.2147/COPD.S144312

13. Vestbo J, Prescott E, Lange P. Copenhagen City Heart Study group. Association of chronic mucus hypersecretion with FEV1 decline and chronic obstructive pulmonary disease morbidity. Am J Respir Crit Care Med. 1996;153(5):1530-1535. doi: https://doi.org/10.1164/ajrccm.153.5.8630597
14. Lange P, Nyboe J, Appleyard M, Jensen G, Schnohr P. Relation of ventilatory impairment and of chronic mucus hypersecretion to mortality from obstructive lung disease and from all causes. Thorax. 1990;45(8):579-585.

doi: https://doi.org/10.1136/thx.45.8.579

15. Ramos FL, Krahnke JS, Kim V. Clinical issues of mucus accumulation in COPD. Int $J$ Chron Obtruct Pulmon Dis. 2014;9:139-150. doi: https://doi.org/10.2147/COPD.S38938

16. Muro S. Cigarette smoking is the most important causal factor for developing chronic obstructive pulmonary disease. Nihon Rinsho. 2011;69(10):1735-1740.

17. Nadel JA, Burgel PR. The role of epidermal growth factor in mucus production. Curr Opin Pharmacol. 2001;1(3):254-258. doi: https://doi.org/10.1016/S1471-4892(01)00045-5

18. Allinson JP, Hardy R, Donaldson GC, Shaheen SO, Kuh D, Wedzicha JA. The presence of chronic mucus hypersecretion across adult life in relation to chronic obstructive pulmonary disease development. Am J Respir Crit Care Med. 2016;193(6):662672. doi: https://doi.org/10.1164/rccm.201511-22100C

19. Button B, Goodell HP, Atieh E, et al. Roles of mucus adhesion and cohesion in cough clearance. PNAS. 2018,115(49):1250112506. doi: https://doi.org/10.1073/pnas.1811787115

20. Rogers DF. Mucoactive agents for airway mucus hypersecretory diseases. Resp Care. 2007;2(9):1176-1197.

21. Balsamo R, Lanata L. Egan CG. Mucoactive drugs. Eur Respir Rev. 2010;19(116):127-133.

doi: https://doi.org/10.1183/09059180.00003510

22. Albrecht HH, Dicpinigaitis PV, Guenin EP. Role of guaifenesin in the management of chronic bronchitis and upper respiratory tract infections. Multidiscip Respir Med. 2017;12:31. doi: https://doi.org/10.1186/s40248-017-0113-4

23. Chodosh S. Glyceryl guaicolate: a controlled laboratory and clinical study. Am Rev Respir Disease. 1964; 90:285-286

24. Chodosh S, Medici TC, Enslein K. Objective sputum changes associated with glyceryl guiacolate in chronic bronchial diseases. Bull Physiopathol Respir. 1973;9:452-456.

25. Thomson ML, Pavia D, McNicol MW. A preliminary study of the effect of guaifenesin on mucociliary clearance from the human lung. Thorax.1973;28:742-747. doi: https://doi.org/10.1136/thx.28.6.742

26. Dicpinigaitis PV, Gayle YE. Effect of guaifenesin on cough reflex sensitivity. Chest. 2003;124(6): 2178-2181. doi: https://doi.org/10.1378/chest.124.6.2178

27. Kagan L, Lavy E, Hoffman A. Effect of mode of administration on guaifenesin pharmacokinetics and expectorant action in the rat model. Pulm Pharmacol Ther. 2009;22(3):250-255. doi: https://doi.org/10.1016/j.pupt.2008.12.020 
28. Seagrave J, Albrecht H, Park YS, Rubin B, Solomon G, et al. Effect of guaifenesin on mucin production, rheology, and mucociliary transport in differentiated human airway epithelial cells. Exp. Lung Res. 2011;37(10):606-614.

doi: https://doi.org/10.3109/01902148.2011.623116

29. Seagrave J, Albrecht HH, Hill DB, Rogers DF, Solomon G. Effects of guaifenesin, $\mathrm{N}$-acetylcysteine, and ambroxol on MUC5AC and mucociliary transport in primary differentiated human tracheal-bronchial cells. Respir Res. 2012;13(1):98.

doi: https://doi.org/10.1186/1465-9921-13-98

30. Boyd E. Expectorants and respiratory tract fluid. Pharmacol Rev.1974;6:521-542.

31. Ziment I. Respiratory Pharmacology and Therapeutics. Philadelphia, PA: WB Saunders;1978

32. Wanner A, Salathe M, O’Riordan T. Mucociliary clearance in the airways:state of the art. Am J Respir Crit Care Med.1996;154(6):1868-1902.

doi: https://doi.org/10.1164/ajrccm.154.6.8970383

33. German V, Corrales R, Ueki I, Nadel J. Reflex stimulation of tracheal mucus gland secretion by gastric irritation in cats. $J$ Appl Physiol. 1982;52(5):1153-1155.

doi: https://doi.org/10.1152/jappl.1982.52.5.1153

34. Yuta A, Baraniuk JN. Therapeutic approaches to mucus hypersecretion. Curr Allergy Asthma Rep. 2005;5(1):243-251. doi: https://doi.org/10.1007/s11882-005-0044-6

35. Ziment I. Theophylline and mucociliary clearance. Chest.1987;92(1):38S-43S.

doi: https://doi.org/10.1378/chest.92.1_Supplement.38S

36. U.S. Department of Health and Human Services. Cold, cough, allergy, bronchodilator and antihistaminic drug products for over-the- counter human use; expectorant drug products for over-the-counter human use; Final Monograph. 21 CFR 341. Washington, DC: Federal Register, U.S. Department of Health and Human Services; 1989.

37. Hayes EW, Jacobs LS. A clinical evaluation of the effectiveness of Robitussin in chronic cough. Chest.1956;30(4):441-448. doi: https://doi.org/10.1378/chest.30.4.441

38. Wójcicki J, Samochowiec L, Szwed G, Sawiński J. The use of Duopect as expectorant-antitussive agent. Arch Immunol Ther Exp.1975;23(1):135-142.

39. Finiguerra M. Guaifenesin in chronic hypersecretion bronchopneumopathy: double-blind placebo-controlled clinical study. Clin. Europa.1982;21(4):751-764.

40. Martindale. Guaifenesin. In: Sweetman S, ed. Martindale: The Complete Drug Reference. London, England, United Kingdom: The Pharmaceutical Press; 2016.
41. Storms WW, Miller JE. Improved lung function and quality of life following guaifenesin treatment in a patient with chronic obstructive pulmonary disease (COPD): a case report. Respir Med Case Rep. 2018;24:84-85.

doi: https://doi.org/10.1016/j.rmcr.2018.04.009

42. Storms WW, Miller JE. Daily use of guaifenesin (Mucinex) in a patient with chronic bronchitis and pathologic mucus hypersecretion: a case report. Respir Med Case Rep. 2018;23:156157. doi: https://doi.org/10.1016/j.rmcr.2018.02.009

43. Singer E, Miller JE. Improved quality of life associated with longterm use of guaifenesin in a patient with chronic obstructive pulmonary disease (COPD) \& stable chronic bronchitis: a case report. Respir Med Case Rep. 2019;26:9-10. doi: https://doi.org/10.1016/j.rmcr.2018.11.002

44. Hooker T. Long-term use of guaifenesin in a patient with COPD, chronic bronchitis and multiple recurring infections. Am J Respir Crit Care Med. 2018;197:A2169.

45. Global Initiative for Chronic Obstructive Lung Disease (GOLD). Global strategy for the diagnosis, management, and prevention of chronic obstructive pulmonary disease, 2019. https:// goldcopd.org/wp-content/uploads/2018/11/GOLD-2019-v1.7FINAL-14Nov2018-WMS.pdf

Published December 2018. Accessed: April 2019

46. Brown DW, Pleasants R, Ohar JA, et al. Health-related quality of life and chronic obstructive pulmonary disease in North Carolina. N Am J Med Sci. 2010;2(2):60-65.

47. Miravitlles M, Anzueto A, Legnani D, Forstmeier L, Fargel M. Patient's perception of exacerbations of COPD-the PERCEIVE study. Respir Med. 2007;101(3):453-460. doi: https://doi.org/10.1016/j.rmed.2006.07.010

48. Monteagudo M, Rodríguez-Blanco T, Llagostera M, et al. Factors associated with changes in quality of life of COPD patients: a prospective study in primary care. Respir Med. 2013;107(10):15891597. doi: https://doi.org/10.1016/j.rmed.2013.05.009

49. Price D, Small M, Milligan G, Higgins V, Garcia Gil E, Estruch J. Impact of night-time symptoms in COPD: a real-world study in five European countries. Int J Chron Obstruct Pulmon Dis. 2013;8:595-603. doi: https://doi.org/10.2147/COPD.S48570

50. Roche N, Chavannes NH, Miravitlles M. COPD symptoms in the morning: impact, evaluation and management. Respir Res. 2013;14:112. doi: https://doi.org/10.1186/1465-9921-14-112

51. Tsiligianni I, Kocks J, Tzanakis N, Siafakas N, van der Molen T. Factors that influence disease-specific quality of life or health status in patients with COPD: a review and meta-analysis of Pearson correlations. Prim Care Respir J. 2011;20:257-268. doi: https://doi.org/10.4104/pcrj.2011.00029 
52. Doyle T, Palmer S, Johnson J, et al. Association of anxiety and depression with pulmonary-specific symptoms in chronic obstructive pulmonary disease. Int J Psychiatry Med. 2013;45(2):189-202. doi: https://doi.org/10.2190/PM.45.2.g

53. Roche N, Small M, Broomfield S, Higgins V, Pollard R. Real world COPD: association of morning symptoms with clinical and patient reported outcomes. COPD. 2013;10(6):679-686. doi: https://doi.org/10.3109/15412555.2013.844784

54. Centers for Disease Control and Prevention (CDC). Antibiotic/ antimicrobial resistance (AR/AMR). Biggest threats and data. CDC website. https://www.cdc.gov/drugresistance/biggest_ threats.html.

Published: 2013. Updated: 2018. Accessed: September 2019

55. Centers for Disease Control and Prevention (CDC). Healthcareassociated infections. Clostridioides difficile infection. CDC website. https://www.cdc.gov/hai/organisms/cdiff/cdiff_infect. html.

Published: 2015. Accessed: September 2019 